\title{
The technique for less infectious and earlier healing of stoma closure wound: negative pressure wound therapy with instillation and dwelling followed by primary closure
}

Yoshinori Yane ${ }^{1 *} \mathbb{D}$, Jin-ichi Hida ${ }^{2}$, Yusuke Makutani ${ }^{1}$, Hokuto Ushijima ${ }^{1}$, Yasumasa Yoshioka', Masayoshi Iwamoto ${ }^{1}$, Toshiaki Wada ${ }^{1}$, Koji Daito ${ }^{1}$, Tadao Tokoro ${ }^{1}$, Kazuki Ueda ${ }^{1}$ and Junichiro Kawamura ${ }^{1}$

\begin{abstract}
Background: Temporary stomas have been widely used to avoid the risk of complications such as anastomotic leakage after colorectal resection. Stoma closure is relatively easy; however, postoperative surgical site infection (SSI) may be a problem. Various methods have been used to reduce the incidence of SSI. We aimed to evaluate a new technique for stoma wound closure.

Methods: We enrolled patients who underwent stoma closure at our hospital between September 2019 and May 2020. We selected patients who lived far from our hospital and had difficulty visiting the hospital regularly and who agreed to undergo this surgical technique. We used negative pressure wound therapy with instillation and dwelling (NPWTi-d) and delayed primary closure for these patients.
\end{abstract}

Results: Four patients underwent NPWTi-d and delayed primary closure without the occurrence of SSI. The median postoperative hospital stay was 9 days (range: 7-14 days), and the median number of days to confirmation of epithelialization was 11.5 days (range: $10-16$ days).

Conclusion: The combined use of NPWTi-d and delayed primary closure for the stoma wound was very effective. This method may be a valuable new technique for wound management after stoma closure.

Keywords: Stoma closure, Surgical site infection, SSI, NPWTi-d, Delayed primary closure, V.A.C. VERAFLO Therapy

\section{Background}

The frequency of temporary stoma creation has increased because of improved techniques of sphinctersaving surgery for lower rectal cancer. Stoma closure is a relatively easy operation; however, surgical site infection (SSI) following stoma closure increases the burden on patients, duration of admission, and medical costs

\footnotetext{
*Correspondence: yaneyoshinori0127@med.kindai.ac.jp

1 Department of Surgery, Faculty of Medicine, Kindai University,

Osaka-sayama, Osaka, Japan

Full list of author information is available at the end of the article
}

[1]. Furthermore, as a serious late complication of stoma closure, SSI may be a risk factor for abdominal incisional hernia formation [2].

The usual method for skin closure at the stoma site is primary suturing; however, the incidence of SSI is reportedly as high as $40 \%$ [3]. Therefore, purse-string skin closure has been widely used as a preventive measure [4]. Another method that has been reported is negative pressure wound therapy (NPWT) [5, 6]. In NPWT, a sealed wound dressing attached to a vacuum pump sucks fluid away from the wound and is thought to promote angiogenesis, reduce edema, increase tensile strength, and 
reduce SSI. However, there are few reports of the use of NPWT for stoma closure, and its efficacy has not been clearly shown. Purse-string skin closure is reportedly very successful for SSI prevention [4]; however, epithelialization of the wound takes a long time [7]. NPWT is very useful for granulation; however, there are cases in which local infection developed [5].

The use of NPWT with instillation and dwelling (NPWTi-d) is gaining interest. NPWTi-d has the benefits of NPWT, with additional automatic cleaning of the wound surface and dissolving of devitalized tissue for removal. It can assist with early, aggressive removal of exudate and be used to lessen the bacterial load. Although NPWTi-d was initially used largely as a lastresort therapy and is currently used in various types of wound, it has not been shown to be effective for use in stoma closure.

We hypothesized that the use of NPWTi-d for stoma wound closure could reduce the risk of infection and improve wound management. However, the time to epithelialization of the wound and consequent burden on patients may still be relatively long. Therefore, in addition to the use of NPWTi-d, we believed that delayed primary closure might reduce the burden of treatment and shorten the postoperative hospital stay, and the number of outpatient visits.

\section{Methods \\ Patients}

Between September 2019 and May 2020, we performed 20 stoma closures at our hospital. We selected patients who lived far from our hospital and had difficulty visiting the hospital regularly, who wanted to try this surgical technique.

\section{Surgical technique}

A spindle-shaped skin incision was made in the craniocaudal direction with a length three times the lateral diameter of the stoma (Fig. 1). The subcutaneous tissue around the stoma was incised, and the adhesions around the small bowel were detached from the abdominal wall. After the small bowel had been mobilized, the segment that had remained outside the abdominal wall was excised. A functional end-to-end anastomosis was then created. Interrupted sutures (0 polydioxanone, PDS ${ }^{\circledR}$, Ethicon, Cincinnati, Ohio., USA) were used for fascial closure. After confirming hemostasis, the subcutaneous tissue was washed with $1500 \mathrm{ml}$ of physiological saline. The subcutaneous tissue and skin were not sutured, and NPWTi-d (V.A.C. VERAFLO Therapy, KCI, an Acelity

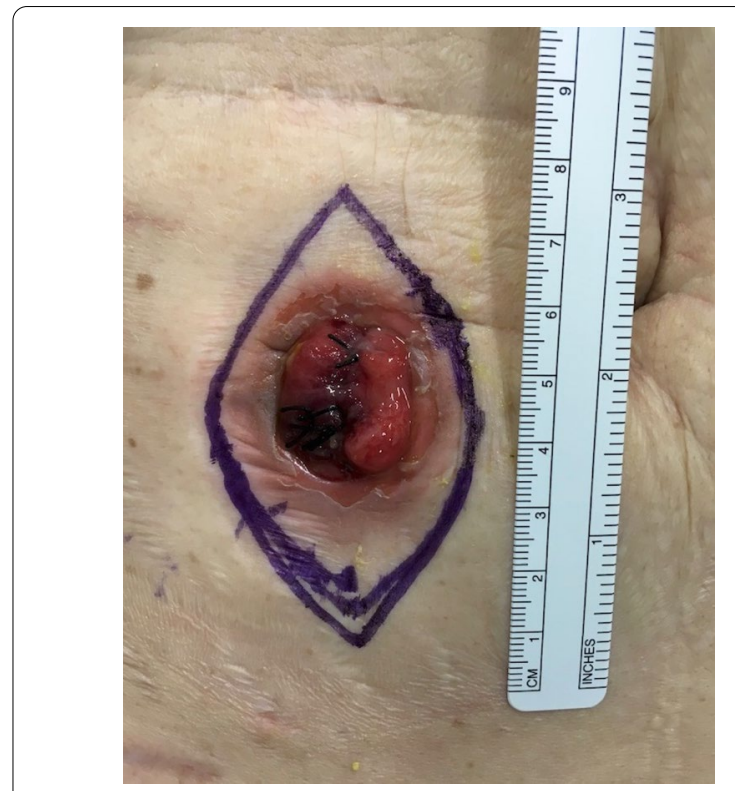

Fig. 1 A spindle-shaped skin incision was made in the cranio-caudal direction with a length three times the lateral diameter of the stoma

Company, San Antonio, Texas) was attached directly to the wound (Fig.2a-c).

\section{Preoperative and postoperative care}

According to our hospital protocol, all patients who underwent stoma closure received mechanical preparation with oral laxatives. Antibiotic prophylaxis, $1.0 \mathrm{~g}$ flomoxef sodium (Flumarin $^{\circledR}$, Shionogi \& Co., LTD, Osaka, Japan) was administered 30 min before the incision, and a single additional dose was given $3 \mathrm{~h}$ after surgery. The first drink was given on postoperative day 1 (POD1), and the first solid oral intake was POD3.

\section{NPWTi-d and delayed primary closure}

Immediately after surgery, NPWTi-d was attached to the wound and treatment was started. The V.A.C. Vera$\mathrm{Flo}^{\mathrm{TM}}$ settings were set to an instill volume of $2 \mathrm{ml}$, soak time of 2 min and a V.A.C. ${ }^{\circledR}$ therapy time of 2 h. The target pressure was $75 \mathrm{mmHg}$, and the intensity was low. The foam was removed at POD 3 or POD 4. If it was confirmed that the granulation had covered the abdominal rectus muscle fascia and the sutures, and there was no obstruction of blood flow in the granulation, delayed primary closure was performed (Fig. 3). The wound was washed with $100 \mathrm{ml}$ of physiological saline, and subcuticular sutures (4-0 PDS) were used (Fig. 4a). The epidermis was reinforced with SteriStrip $^{\mathrm{TM}}$ skin closures (3 M Japan Limited, Tokyo, Japan) to reduce tension on the sutures (Fig. 4b). 

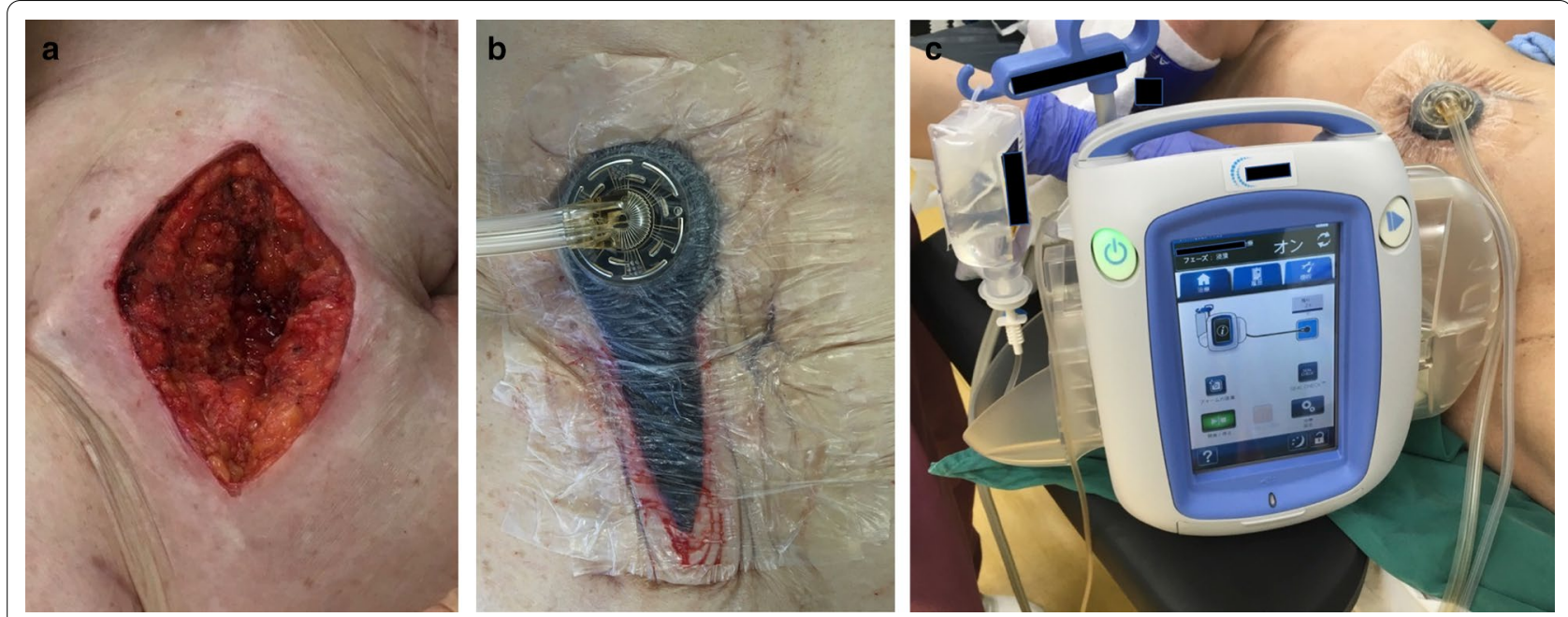

Fig. 2 Fascial closure was performed to an interrupted manner with an 0 polydioxanone suture $\left(\mathrm{PDS}^{\circledR}\right)$. Subcutaneous tissue and skin was not sutured (a). V.A.C. VeraFlo ${ }^{\mathrm{TM}}$ was attached to the wound $(\mathbf{b}, \mathbf{c})$

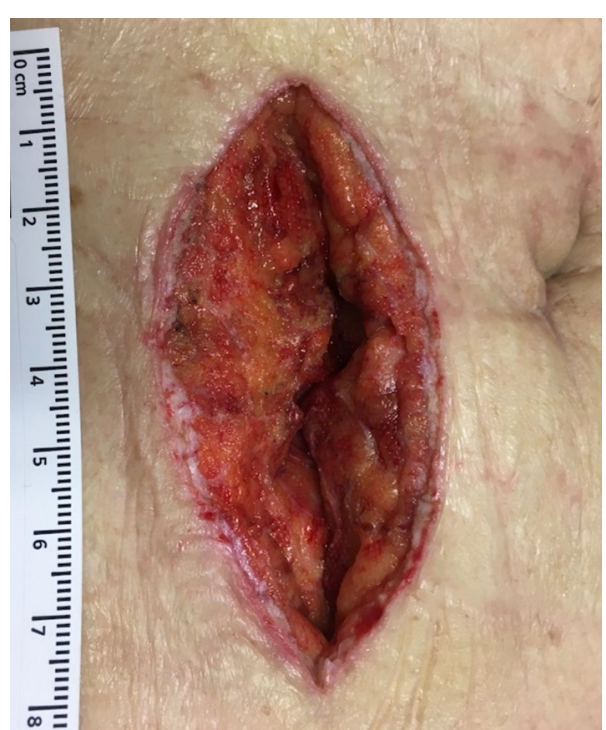

Fig. 3 The granulation had grown to the extent that the abdominal rectus muscle fascia and the suture was covered. There was no obstruction of blood flow in the granulation

\section{Results}

Four patients were treated with NPWTi-d and delayed primary closure for wound management. There were 3 males and 1 female. The median age was 72 years (range: 44-75 years). The median body mass index (BMI) was $20.7 \mathrm{~kg} / \mathrm{m}^{2}$ (range: $17.6-36.9 \mathrm{~kg} / \mathrm{m}^{2}$ ). One patient was obese $\left(\mathrm{BMI}>30 \mathrm{~kg} / \mathrm{m}^{2}\right)$. One patient $(25 \%)$ had a history of diabetes mellitus, and one patient (25\%) had received chemotherapy. Two patients (50\%) were smokers. Three patients $(75 \%)$ had a low anterior resection, and 1 patient
(25\%) had a high anterior resection for rectal cancer. All patients had a subsequent ileostomy (Table 1).

Table 2 presents the details of stoma closure and outcomes. No wound bleeding was observed during NPWTi-d. In all cases, the first foam exchange was performed on POD 3 or 4 and delayed primary closure was performed because granulation had grown enough to cover the abdominal rectus muscle fascia and the sutures.

No SSI was observed postoperatively. One patient had postoperative ileus. The median postoperative hospital stay was 9 days (range: 7-14 days), the median number of days to confirm epithelialization was 11.5 days (range: 10-16 days), and the number of outpatient visits after leaving hospital was 0 or 1 .

\section{Discussion}

We found that closure using NPWTi-d and delayed primary closure was an effective therapy for stoma wound closure. There were no cases of SSI, and the burden on medical staff and patients during hospitalization was, therefore, decreased. In addition, the patients did not have to treat the wound themselves after discharge and had fewer outpatient visits.

A temporary stoma is commonly used when a low pelvic anastomosis is performed in rectal cancer and benign diseases. The most dreaded complication of a low pelvic anastomosis is an anastomotic leak; therefore, a temporary stoma is performed $[8,9]$.

SSI is an important and common complication after stoma closure. Peristomal skin reportedly harbors a considerable number of enteric bacteria, and since the procedure also entails enteric anastomosis, stoma closure is considered a clean-contaminated procedure [10]. 

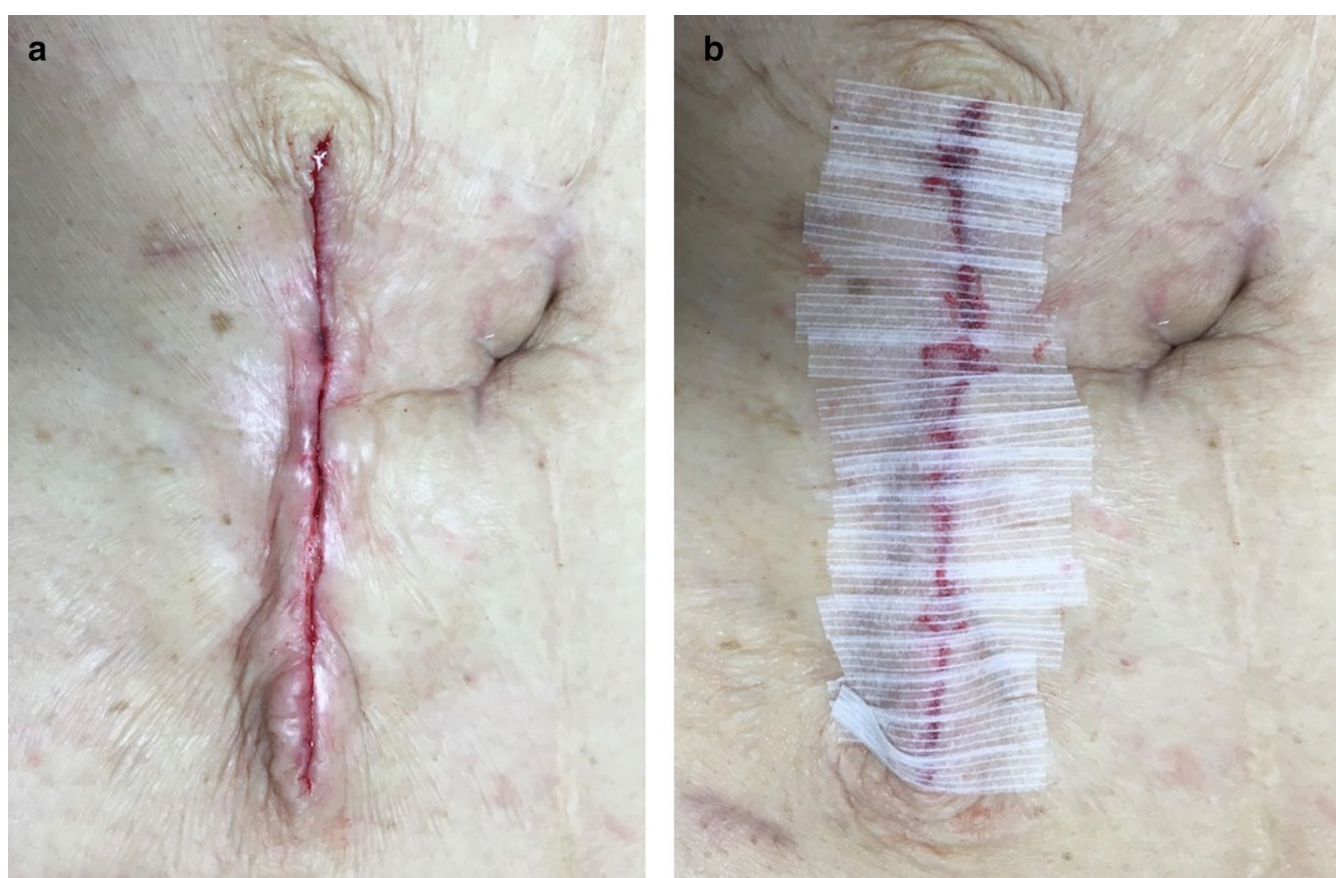

Fig. 4 It was performed delayed primary closure by subcuticular suture with 4-0 PDS (a). The epidermis was reinforced with $3 M^{{ }^{\mathrm{TM}}}$ Steri-Strip ${ }^{\mathrm{TM}}$ Skin Closures (b)

Generally, risk factors for SSI include radiation therapy, chemotherapy, obesity, diabetes, long-term steroid administration, and immunosuppressant administration $[11,12]$. SSI is associated with an increased burden of treatment for medical staff and patients. It causes prolonged postoperative hospital stay, increase in outpatient visits, additional home health care utilization, and increased medical costs. Additionally, as a late complication of SSI after stoma closure, an abdominal incisional hernia may develop. An abdominal incisional hernia can significantly reduce a patient's quality of life and may require re-operation. It therefore leads to a further increase in medical costs.

Other steps have been taken to reduce SSI following stoma closure. With primary suture closure, the wound is closed immediately, and a dead space is formed. The subcutaneous fluids cannot drain, and an abscess may form. There are some reports of adding a drainage tube to the subcutaneous layer under the wound; however, this also has a high infection rate of about $20 \%$ [11].

Purse-string suturing has one of the lowest infection rates, and its usefulness has been demonstrated [ 1 , $4,11]$. However, this method can take up to 30 days for granulation and epithelialization [13]. Continuous wound care and outpatient visits are required until the wound is healed, and it may be difficult for elderly patients to perform self-care procedures such as cleaning the wound. NPWT therapy is thought to promote granulation and wound healing. It increases wound blood flow, promotes granulation tissue formation, reduces edema, and removes exudate and inactive tissue by sealing the wound and applying negative pressure drainage. Currently, although NPWT is used for various surgical cases, its prophylactic use is still not considered vital in digestive surgery. A study on the use of NPWT in the prevention of SSI and shortening of wound healing period after stoma closure was not able to show the efficacy of NPWT compared to that of purse-string sutures in significantly reducing the wound healing time [5]. Additionally, local infection may occur as an adverse event with NPWT [5, 14].

NPWTi-d can prevent bacterial growth by automatic cleansing of the wound surface and removal of dissolving devitalized tissue and exudate early and aggressively. By using NPWTi-d on the stoma closure wound, the promotion of granulation may reduce the dead space and the risk of SSI [15-21]. It may also shorten the wound healing period. Additionally, delayed primary closure may further shorten the epithelialization time. This will reduce the burden on medical staff and patients and lead to a reduction in inpatient duration and outpatient visits.

This study has several limitations. First, this study had a very small sample size. Second, this was a non-controlled retrospective cohort study. The future study should be 


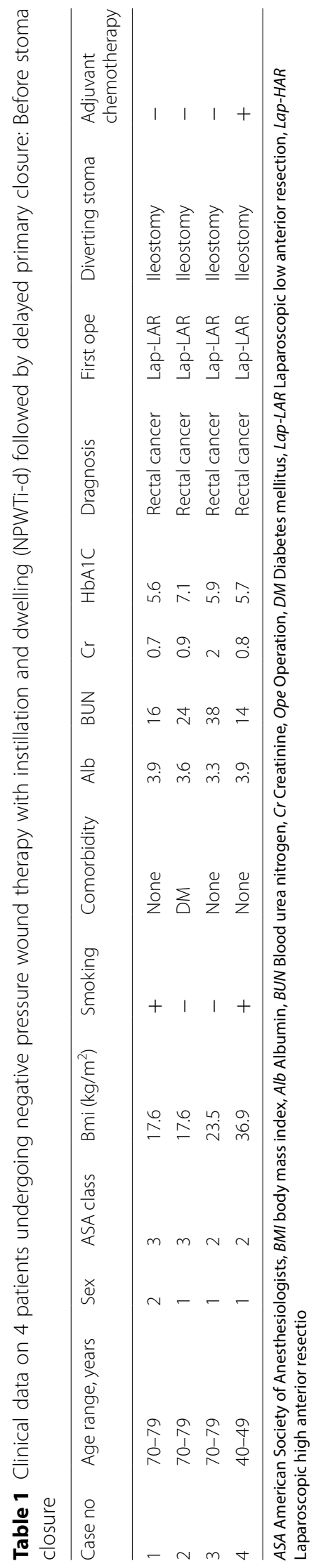


Table 2 Clinical data on 4 patients undergoing negative pressure wound therapy with instillation and dwelling (NPWTi-d) followed by delayed primary closure: After stoma closure

\begin{tabular}{lllllllll}
\hline Case no & $\begin{array}{l}\text { Stoma closure } \\
\text { day after 1 stope }\end{array}$ & $\begin{array}{l}\text { Stoma closure } \\
\text { ope. Time (min) }\end{array}$ & $\begin{array}{l}\text { Duration of } \\
\text { NPWTi-d }\end{array}$ & $\begin{array}{l}\text { Postoperative } \\
\text { hospital stay } \\
\text { (days) }\end{array}$ & $\begin{array}{l}\text { Outpatient visit after } \\
\text { discharge (times) }\end{array}$ & $\begin{array}{l}\text { Wound healed } \\
\text { (postoperative } \\
\text { days) }\end{array}$ & $\begin{array}{c}\text { Post ope. course } \\
\text { (1) }\end{array}$ \\
\hline 1 & 175 & 75 & 3 & - & 11 & 0 & 11 & Unremarkable \\
2 & 119 & 102 & 3 & - & 14 & 1 & 10 & SBO \\
3 & 150 & 74 & 4 & -7 & 1 & 16 & Unremarkable \\
4 & 210 & 103 & 4 & -7 & 1 & Unremarkable \\
\hline
\end{tabular}

NPWTi-d Negative Pressure Wound Therapy with instillation and dwelling, SSI Surgical site infection, SBO Small bowel obstruction

comparing the effects of NPWTi-d with those of purse string closure or primary closure. Third, it was not verified for cost-effectiveness. The cost-effectiveness should be assessed of NPWTi-d for preventing surgical site infection.

\section{Conclusions}

Combined treatment with NPWTi-d and delayed primary closure of stoma closure wounds may be a new wound management technique, which can reduce the risk of SSI and shorten the wound healing period. In the future, it is desirable to study with a larger sample size.

\section{Abbreviations}

SSI: Surgical site Infection; NPWTi-d: Negative pressure wound therapy with instillation and dwelling; NPWT: Negative pressure wound therapy; POD: Postoperative day; BMI: Body Mass Index.

\section{Acknowledgements}

We would like to thank Editage (www.editage.com) for English language editing.

\section{Authors' contributions}

All authors contributed to the study conception and design. Material preparation, data collection and analysis were performed by YY1 (first author), JH, YM, $H U, Y Y 2, M I, T W, K D$, and JK. The first draft of the manuscript was written by YY1 (first author). JH, KD, TT, KU, and JK commented on previous versions of the manuscript. All authors read and approved the final manuscript.

\section{Funding}

This research did not receive any specific grant from funding agencies in the public, commercial, or not-for-profit sectors.

\section{Availability of data and materials}

Not applicable.

\section{Ethics approval and consent to participate}

All procedures performed in studies involving human participants were in accordance with the ethical standards of the institutional and/or national research committee and with the 1964 Helsinki declaration and its later amendments or comparable ethical standards. Further, this study was approved by the Institutional Ethical Review Boards of Kindai University (approval no. 2019-031).

\section{Consent to participate}

Written informed consent was obtained from all individual participants included in the study.

\section{Consent for publication}

All authors have approved the final version of the manuscript and agree with submission to BMC Surgery.

\section{Competing interests:}

The authors have no conflicts interest to disclose.

\section{Author details}

${ }^{1}$ Department of Surgery, Faculty of Medicine, Kindai University, Osaka-sayama, Osaka, Japan. ${ }^{2}$ Department of Gastroenterological Surgery, Kindai University Nara Hospital, Ikoma, Nara, Japan.

Received: 17 September 2020 Accepted: 18 February 2021

Published online: 22 March 2021

\section{References}

1. LiTL, Brahmbhatt R, Hicks CS. Prevalence of surgical site infection at the stoma site following four skin closure techniques: a retrospective cohort study. Dig Surg. 2014;31(2):73-8. https://doi.org/10.1159/000354426.

2. Murray WB, Cipher JD, Pham T. The impact of surgical site infection on the development of incisional hernia and small bowel obstruction in colorectal surgery. AM J Surg. 2011;202:558-60. https://doi.org/10.1016/j. amjsurg.2011.06.014.

3. Milanchi S, Nasseri Y, Kindner T. Wound infection after ileostomy closure can be eliminated by circumferential subcuticular wound approximation. Dis Colon Rectum. 2009;52:469-74. https://doi.org/10.1007/DCR.0b013 e31819acc90

4. McCartan PD, Burke PJ, Walsh RS, Coffey CJ. Purse-string approximation is superior to primary skin closure following stoma reversal: a systematic review and meta-analysis. Tech Coloproctol. 2013;17:345-51. https://doi. org/10.1007/s10151-012-0970-y.

5. Uchino M, Hirose K, Bando T, Chohno T, Takesue Y, Ikeuchi H. Randomized controlled trial of prophylactic negative-pressure wound therapy at ostomy closure for the prevention of delayed wound healing and surgical site infection in patients with ulcerative colitis. Dig Surg. 2016;33:449-54. https://doi.org/10.1159/000446550.

6. Kim S, Kang IS. The effectiveness of negative-pressure wound therapy for wound healing after stoma reversal: a randomized control study (SR-PICO study). Trials. 2020;21:24. https://doi.org/10.1186/s13063-019-3925-z.

7. Amamo K, Ishida H, Kumamoto K, et al. Purse-string approximation vs. primary closure with a drain for stoma reversal surgery: results of a randomized clinical trial. Surg Today. 2019;49:231-7. https://doi.org/10.1007/ s00595-018-1729-5.

8. Mimezami A, Mimezami R, Chandrakumaran K, et al. Increased local recurrence and reduced survival from colorectal cancer following anastomotic leak: systematic review and meta-analysis. Ann Surg. 2011;253:890-9. https://doi.org/10.1097/SLA.0b013e3182128929.

9. Sharma A, Deeb AP, Rickles AS, et al. Closure of defunctioning loop ileostomy is associated with considerable morbidity. Colorectal Dis. 2013;15:458-62. https://doi.org/10.1111/codi.12029. 
10. Pemmaraju VT, Lansing SS, Husain S. A protocol for skin closure after stoma reversal. Tech Coloproctol. 2020;24:255-7. https://doi.org/10.1007/ s10151-019-02033-7.

11. Fernandez VO, Avila TM, Nesme SN. Multivariate analysis of risk factors for complications after loop ileostomy closure. Cir Cir. 2019;87:337-46. https://doi.org/10.24875/CIRU.18000611.

12. Chu ID, Schlieve RC, Colibaseanu YD, et al. Surgical site infections (SSIs) after stoma reversal (SR): risk factors, implications, and protective strategies. J Gastrointest Surg. 2015;19:327-34. https://doi.org/10.1007/ s11605-014-2649-3.

13. Yoon SI, Bae SM, Namgung H, Park DG. Clinical trial on the incidence of wound infection and patient satisfaction after stoma closure: comparison of two skin closure techniques. Ann Coloproctol. 2015;31:29-33. https:// doi.org/10.3393/ac.2015.31.1.29.

14. Seidel D, Diedrich S, Herrle F, et al. Negative pressure wound therapy vs conventional wound treatment in subcutaneous abdominal wound healing impairment: the SAWHI randomized clinical trial. JAMA Surg. 2020;155(6):469-78. https://doi.org/10.1001/jamasurg.2020.0414.

15. Fernandez R, Griffiths R. Water for wound cleansing. Cochrane Database Syst Rev. 2008. https://doi.org/10.1002/14651858.CD003861.pub2.

16. Wackenfors A, Gustafsson R, Sjogren J, Algotsson L, Ingemans-son R, Malmsjo M. Blood flow responses in the peristernal thoracic wall during vacuum-assisted closure therapy. Ann Thorac Surg. 2005;79:1724-31. https://doi.org/10.1016/j.athoracsur.2004.10.053.
17. Morykwas MJ, Argenta LC, Shelton-Brown El, McGuirt W. Vacuum-assisted closure: a new method for wound control and treatment: animal studies and basic foundation. Ann Plast Surg. 1997;38:553-62. https://doi.org/10. 1097/00000637-199706000-00001.

18. Wackenfors A, Sjogren J, Gustafsson R, Algotsson L, Ingemans-son $R$, Malmsjo M. Effects of vacuum-assisted closure therapy on inguinal wound edge microvascular blood flow. Wound Repair Regen. 2004;12:600-6. https://doi.org/10.1111/j.1067-1927.2004.12602.x.

19. Brinkert D, Ali M, Naud M, Maire N, Trial C, Teot L. Negative pressure wound therapy with saline instillation: 131 patient case series. Int Wound J. 2013;10:56-60. https://doi.org/10.1111/iwj.12176.

20. Fluieraru S, Bekara F, Naud M, et al. Sterile-water negative pressure instillation therapy for complex wounds and NPWT failures. J Wound Care. 2013;22:293-9. https://doi.org/10.12968/jowc.2013.22.6.293.

21. Gupta S, Gabriel A, Lantis J, Téot L. Clinical recommendations and practical guide for negative pressure wound therapy with instillation. Int Wound J. 2016;13:159-74. https://doi.org/10.1111/iwj.12452.

\section{Publisher's Note}

Springer Nature remains neutral with regard to jurisdictional claims in published maps and institutional affiliations.
Ready to submit your research? Choose BMC and benefit from:

- fast, convenient online submission

- thorough peer review by experienced researchers in your field

- rapid publication on acceptance

- support for research data, including large and complex data types

- gold Open Access which fosters wider collaboration and increased citations

- maximum visibility for your research: over $100 \mathrm{M}$ website views per year

At BMC, research is always in progress.

Learn more biomedcentral.com/submissions 